\title{
Grid Impedance Estimation for Islanding Detection and Adaptive Control of Converters
}

\author{
Abdelhady Ghanem ${ }^{1,2^{*}}$, Mohamed Rashed ${ }^{1}$, Mark Sumner ${ }^{1}$, Mohamed. A. Elsayes ${ }^{2}$ and \\ Ibrahim. I. I. Mansy ${ }^{2}$ \\ ${ }^{1}$ Department of Electrical and Electronics Engineering, University of Nottingham, Nottingham, UK. \\ ${ }^{2}$ Electrical Engineering Department, Mansoura University, Mansoura, Egypt. \\ *eexatg@nottingham.ac.uk
}

\begin{abstract}
Power system (grid) impedance is time varying due to the changing structure of the power system configuration and it can have a considerable influence on the control and stability of grid connected converters. This paper presents an online grid impedance estimation method using the output switching current ripple of a SVPWM based grid connected converter. The proposed impedance estimation method is derived from the discretised system model using two consecutive samples within a single switching period. The estimated impedance is used for islanding detection and online current controller parameter tuning. Theoretical analysis and MATLAB simulation results are presented to verify the proposed method and its effectiveness is validated using experimental testing.
\end{abstract}

\section{Introduction}

An increasing number of power electronic converters are being used to connect renewable energy sources to the grid. In recent years, real-time grid impedance estimation has been researched to improve controller stability and protection (e.g. with islanding detection) in these types of converter [1-3]. Methods for grid impedance estimation are generally classified as passive (non-invasive) and active (invasive) [4]. Passive methods use the non-characteristic (harmonic) voltage and current measurements inherently present in the system to estimate impedance whilst active methods deliberately create a disturbance in the grid and the impedance is estimated from the grid response: in general good results can be achieved as the injection gives the measurements used for impedance estimation a high signal to noise ratio (SNR). Passive methods are preferred as they do not create additional disturbances in the grid, however, the SNR is much lower and the estimate tends to be poorer.

Passive methods for example based on the disturbance induced during the connection of a capacitor bank have been presented in [5,6]. In [5], the authors measured the unbalanced voltage and current variation induced by connecting a capacitor bank to only one phase of a $12 \mathrm{kV}$ substation power system. The voltage and current before and after the capacitor bank switching as well as the capacitor current are digitally recorded to estimate the self and mutual system impedance at the harmonic frequencies using the Fast Fourier Transform (FFT). The precision of the results is limited not only by the frequency of the harmonics present but also by their amplitudes, which become very low with respect to noise for higher frequencies. In [6], the voltage and current before and after the switching of a 12 $\mathrm{kV}, 750 \mathrm{kVAr}$ capacitor are recorded to estimate the system impedance. Two frequency domain methods are presented. The first method uses the FFT and is named the direct method: the frequency components of the voltage and current are identified, then the voltage and current spectra are used to find the impedance transfer function. This method was found to produce accurate results when the frequency component SNRs are large. The second method (the indirect method) first obtains an estimate of the voltage and current samples and then auto and cross-correlation functions are employed to reject the frequency components that are contaminated with noise. These functions are then used together with the FFT to find the respective power spectra of the signals, and finally to find the impedance transfer function. However, this second method suffers from false cross correlations between the voltage and current.

A passive grid impedance estimation method based on the inherent switching features (high frequency harmonics) of the grid-connected power converter is presented in [7]. This method achieved fast and accurate impedance estimation. However, the current at the switching frequency is very small, so more consideration for SNR and the measurement of a low amplitude current harmonic superimposed on a large fundamental are required. A grid inductance estimation method based on the excitation of the LCL-filter resonance is proposed in [8]. The technique presented is based on the fact that the frequency peak due to the resonance is particularly sensitive to a change of grid inductance. The limitations of this method include exciting the system resonance in a controlled way and the high number of calculations can overload the processing platform. In [9], an Extended Kalman Filter (EKF) is used to estimate the time variant grid impedance. It uses an observer based parameter identification based on the inherent 
disturbance at the point of common coupling (PCC). The main disadvantage of this method is the complicated tuning processes for the covariance matrices. Another example of a passive method [10] is an analytical estimation model created in the stationary reference frame to estimate the total inductance seen by a variable switching frequency converter using two consecutive current samples. However, the estimated inductance is sensitive to system resistance.

A major drawback of passive techniques is that the grid variations might not be sufficiently large enough to give an accurate estimation of the grid impedance due to the low SNR. Another issue is the time interval at which grid variations occur. It might be the case that no variations appear for a long time, hence no information about grid impedance is known during this time interval. For this reason, it is known that passive methods have a very large nondetection zone.

Several active techniques have been reported in recent years. Ciobotaru et al. [4] presented an online impedance estimation technique based on periodical variations of active and reactive power (PQ variations) of a grid connected single phase power converter. This technique is based on the intentional change of both active and reactive power in order to produce a grid disturbance and hence grid impedance can be estimated. The accuracy of this method depends on the PQ variation values and the duration of the perturbation. In $[11,12]$ a current spike is deliberately injected at the voltage zero crossing instant by a grid connected converter. In order to eliminate the background grid disturbance and harmonics, the voltage and current signals before the injection are measured and subtracted from their signals during the injection. Based on the extracted voltage and current signals, the grid impedance value is determined using a FFT. A similar method employing the Continuous Wavelet Transform (CWT) to derive the impedance from transient data is presented in [13]. The main drawbacks of current spike injection based impedance estimation techniques are that the system ratings may be exceeded and nonlinear system response may be excited. Asiminoaei et al. [14] have used a PV inverter to inject a low frequency non-characteristic harmonic current of $75 \mathrm{~Hz}$ by adding a harmonic voltage to the voltage reference of the PV inverter. A Discrete Fourier Transform (DFT) amplitude and phase calculations are then performed to calculate the grid impedance at that frequency. In [15] an injection of a high frequency signal comprising one or two voltage harmonic signals is implemented. The single harmonic injection uses a $500 \mathrm{~Hz}$ signal and the double harmonic injection uses a $500 \mathrm{~Hz}$ and $600 \mathrm{~Hz}$ signals. The authors in [16], presented a power network parameter estimation based on stimulations injected through a pulse width modulator: it creates a stimulation signal based on Pseudo Random Binary Sequences (PRBS) which have been used to create harmonic-rich stimulation.

Good impedance estimation can be achieved using the aforementioned active methods; however, they suffer from various problems, mainly related to the rate and amplitude of the repeated injections which are usually kept high to increase the SNR and adversely increase the total harmonic distortion. In addition, the estimated impedance accuracy depends on the level of the background harmonics. Furthermore, complicated post-processing is always required which may overload the processing platforms.

In this paper, an improved approach to passive impedance estimation is proposed. It uses closed form models for grid inductance and resistance estimation derived from the discretised system model in a rotating reference frame. It uses two consecutive samples within a single switching period of a SVPWM based converter - it could be argued that it is using the PWM itself as an injection signal to obtain the benefit of improved SNR compared to most passive methods. The proposed impedance estimation technique is capable of identifying the total inductance seen by the converter. However, it is unable to identify the resistance of the grid impedance. The proposed impedance estimation method has the following features: no need for intentional operating point change or external injection, simple postprocessing, fast and sample-by-sample impedance estimation. Furthermore, the new inductance estimator is completely independent of the resistance estimate.

This paper is organized as follows. In section II, the system description and control scheme for a grid connected converter are presented. Section III presents the derivation of the inductance and resistance estimation models. MATLAB based simulation results for different scenarios and applications of the estimated inductance are given and discussed in section IV. Experimental results are presented in section V and finally, conclusions are drawn.

\section{System Description}

A three-phase grid connected converter system is shown in Fig. 1-a. The power converter is connected to the PCC via an inductive filter. The converter is operated in current control mode with a sensorless approach to grid voltage phase angle detection. 


\subsection{Current control loop}

The current control loop using a sensorless grid voltage phase angle detection based on a Phase Locked Loop (PLL) is shown in Fig. 1-b. The error between the reference and actual measured currents in a $d q$ rotating reference frame (synchronised to the grid voltage vector) is processed via a PI controller (together with cross coupling compensation) in order to achieve independent control of active and reactive power and calculate the required converter output reference voltage. A SVPWM technique is used to drive the power converter switches.

It should be noted that PLL based synchronisation methods are sensitive to the voltage at the PCC and their dynamic response can adversely affect the overall system stability especially in high impedance networks [17].

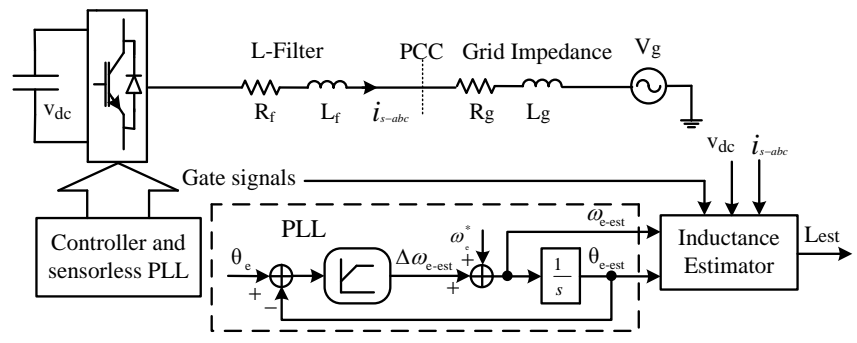

a
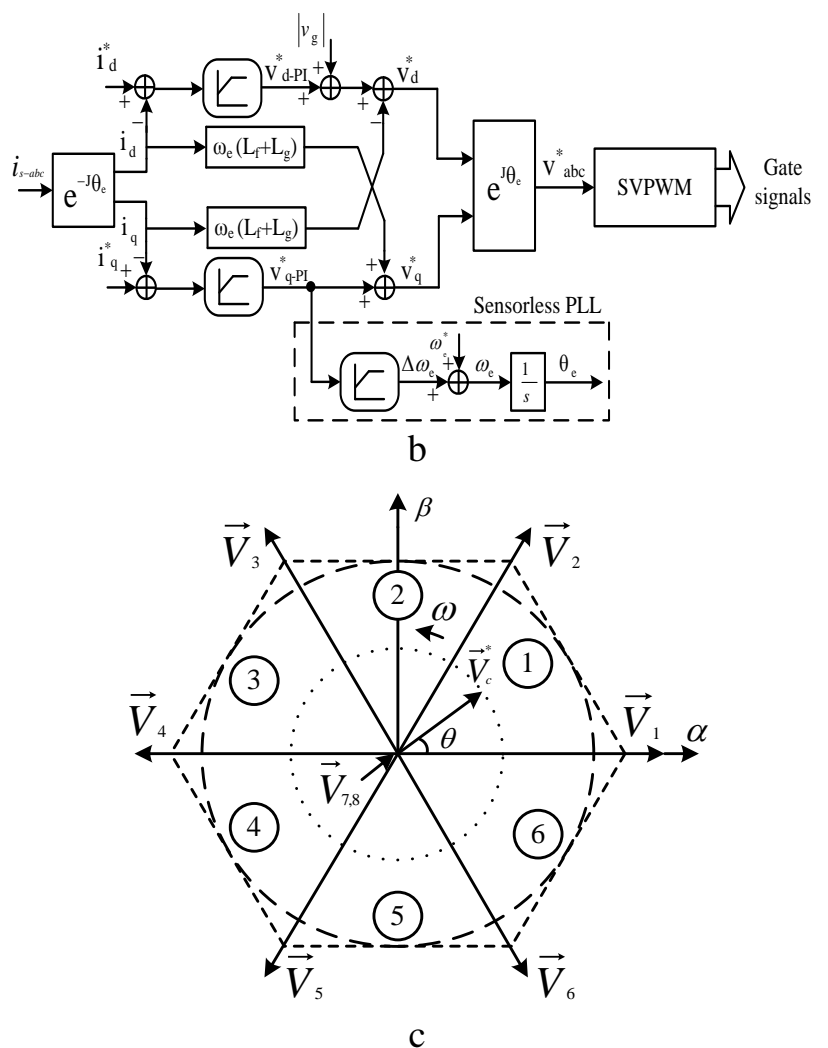

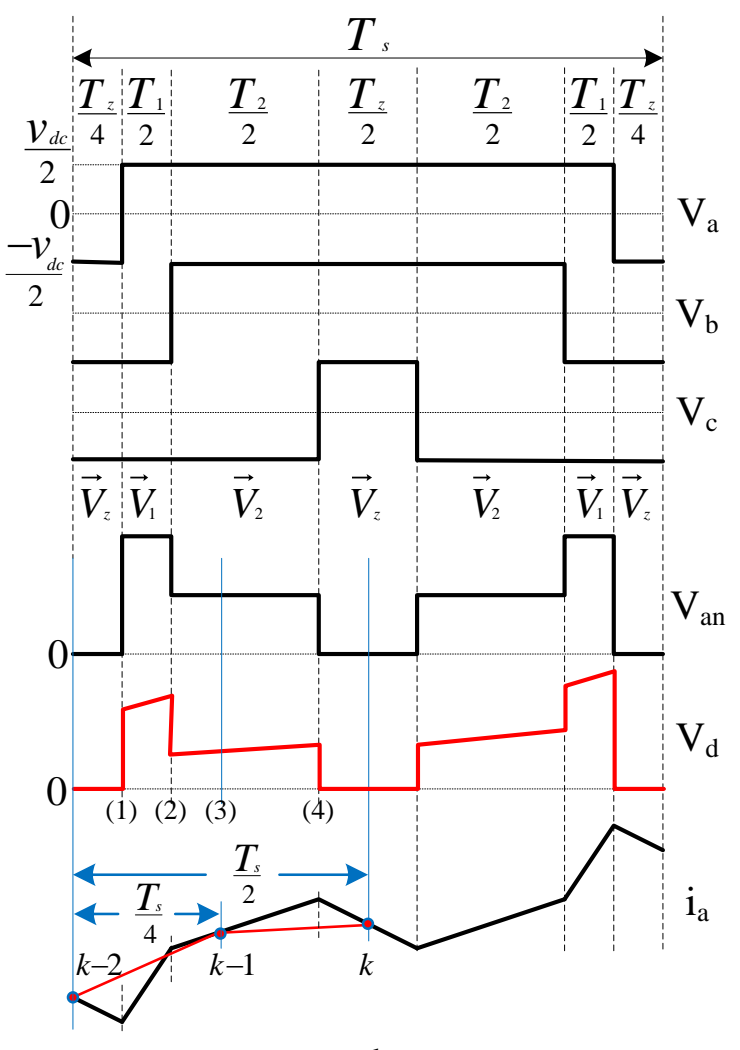

d

Fig. 1. Configuration of grid connected converter and SVPWM.

a Three-phase grid connected converter test system.

b Current control loop with sensorless PLL.

c Basic space vector representation.

d SVPWM and measurement instants.

For grid-connected converters, it is important to extract the synchronizing angle even if the voltage at PCC is highly polluted due to the presence of a large grid impedance. To overcome this problem, a sensorless grid voltage 
detection based PLL is used [18]. The output voltage from the PI controller of the quadrature axis current control loop represents the reference quadrature axis component of the grid voltage $V_{q-P I}^{*}$ and it can be used for synchronization instead of a direct PCC voltage measurement. The PLL is locked by setting $V_{q-P I}^{*}$ to zero as a phase detector. A PI controller is used to control this component by minimizing the phase error. The output of the PI controller is added to a constant value $\omega_{e}^{*}$ which represents the nominal frequency and hence the output is the grid voltage frequency $\omega_{e}$. A Voltage-Controlled Oscillator (VCO), normally an integrator, is then used to extract the grid phase angle $\theta_{e}$ (see Fig. 1-b).

In this paper, the grid impedance estimator proposed uses the current and voltage components measured in the rotating $d q$ reference frame. Therefore, it is important to ensure that the angle used within the inductance estimator algorithm does not have any fast changes associated with it (eg due to noise or step changes within the system). At the same time, fast tracking of the grid voltage is required in order to provide a fast and stable control operation. Therefore, a low bandwidth PLL is used for the impedance estimator as shown in Fig. 1-a in order to ensure separation of the dynamic responses of the control algorithm and the proposed inductance estimator. The output grid voltage angle from the PLL $\theta_{e}$ is fed to a PLL with a significantly lower bandwidth and $\theta_{e-e s t}$ is extracted. $\theta_{e-e s t}$ is used to transform the $a b c$ current and voltage to the $d q$ rotating reference frame used for the impedance estimation only, while $\theta_{e}$ is used within the current controller processes and grid synchronization.

\subsection{Space vector $P W M$}

Fig. 1-c shows a representation of the basic space-vector and the reference voltage vector in the stationary reference frame. It can be seen that the grid connected converter shown in Fig. 1-a has eight switching states $\vec{V}_{1}$ to $\vec{V}_{8}$ where $\vec{V}_{1}$ to $\vec{V}_{6}$ are non-zero voltage vectors form the axes of the hexagon and each $60^{\circ}$ shift, while $\vec{V}_{7}$ and $\vec{V}_{8}$ are zero voltage vectors located at the origin [19]. The objective of the space vector technique is to approximate the reference voltage vector $\vec{V}_{c}^{*}$ with the eight space vectors available in VSI. For instance, if $\vec{V}_{c}^{*}$ lies between two arbitrary vectors $\vec{V}_{i}$, $\vec{V}_{i+1}$, only the nearest non-zero vectors $\left(\vec{V}_{i}, \vec{V}_{i+1}\right)$ and one zero vector $\left(\vec{V}_{7}\right.$ or $\left.\vec{V}_{8}\right)$ should be used. Fig. 1-d shows the space vector implementation in sector one as an example.

The general expressions for each vector time at any sector can be calculated as [19, 20]:

$$
\begin{gathered}
T_{1}=\frac{\sqrt{3} \cdot T_{s} \cdot \vec{V}_{c}^{*}}{V_{d c}} \sin \left(\frac{\pi}{3}-\theta+\frac{\left(s_{n}-1\right) \pi}{3}\right) \\
T_{2}=\frac{\sqrt{3} \cdot T_{s} \cdot \vec{V}_{c}^{*}}{V_{d c}} \sin \left(\theta-\frac{\left(s_{n}-1\right) \pi}{3}\right) \\
T_{z}=T_{s}-T_{1}-T_{2} \\
\vec{V}_{c}^{*}=\sqrt{\left(V_{c \alpha}^{*}\right)^{2}+\left(V_{c \beta}^{*}\right)^{2}} \\
\theta=\tan ^{-1}\left(\frac{V_{c \beta}^{*}}{V_{c \alpha}^{*}}\right)
\end{gathered}
$$

Where; $T_{S}$ is the sampling period, $s_{n}$ is the sector number which can be determined according to the value of converter reference voltage position and $V_{c \alpha}^{*}, V_{c \beta}^{*}$ are the demand $\alpha \beta$ converter voltages derived from the $d$ and $q$ axis current controllers and $\theta_{e}$ from the PLL. 


\section{Impedance Estimation Method}

The total inductance and resistance (grid plus filter) are estimated using two consecutive current samples measured within the SVPWM period and used with the discretised system model in the rotating $d q$ frame. For the grid connected converter shown in Fig. 1, the continuous-time model in the $d q$ frame is:

$$
\frac{d}{d t} i_{d q}=\frac{1}{L}\left(v_{c d q}-R i_{d q}-j \omega_{e} L i_{d q}-v_{g d q}\right)
$$

where subscript $d q$ denotes the axes of an arbitrary rotating $d q$ frame. c and g refer to converter and grid respectively. Fig. 1-d shows typical PWM outputs in sector one and the three fixed measurement instants in each sampling period, which are marked as $k-2$ at the beginning, $k-1$ at $T s / 4$ and $k$ at the middle of the sampling period. It should be noted from Fig. 1-d that the converter output phase voltage waveforms are constant during the time intervals of the voltage vectors $\mathrm{V}_{1}$ and $\mathrm{V}_{2}$, which e.g. for $\mathrm{V}_{1}$ are equal to $v_{a n}=2 V_{d d} / 3, v_{b n}=-V_{d d} / 3$ and $v_{c n}=-V_{d d} / 3$. However the equivalent instantaneous $d q$ voltage components during these time intervals are time varying, (see vd waveform in Fig. 1-d). Therefore, the discrete form of (6) is given in (7 and 8), where subscript " $a v$ " denotes average value, e.g. the discrete voltage $v_{c d q-a v}^{k-1}$ is the average value of the instantaneous voltage waveform $v_{c d q}(t)$ over the time interval between the sampling instants $k-1$ and $k$. The current derivatives in (6) are approximated using the Forward Euler method. The discrete model of (6) for two consecutive samples $k$ and $k-l$ is expressed as:

$$
\begin{aligned}
& i_{d q}^{k}=i_{d q}^{k-1}+\frac{T_{s}}{4 L}\left(v_{c d q-a v}^{k-1}-R i_{d q-a v}^{k-1}-j \omega_{e} i_{d q-a v}^{k-1}-v_{g d q-a v}^{k-1}\right) \\
& i_{d q}^{k-1}=i_{d q}^{k-2}+\frac{T_{s}}{4 L}\left(v_{c d q-a v}^{k-2}-R i_{d q-a v}^{k-2}-j \omega_{e} i_{d q-a v}^{k-2}-v_{g d q-a v}^{k-2}\right)
\end{aligned}
$$

where;

$$
\begin{gathered}
i_{d q-a v}^{k-2}=0.5 \times\left(i_{d q}^{k-2}+i_{d q}^{k-1}\right) \\
i_{d q-a v}^{k-1}=0.5 \times\left(i_{d q}^{k-1}+i_{d q}^{k}\right) \\
v_{c d q-a v}^{k-2}=\left(\frac{1}{T_{s}-T_{z}}\right)\left[\left(v_{c d q}^{(1)}+v_{c d q}^{(2)}\right) \frac{T_{1}}{2}+\left(v_{c d q}^{(2)}+v_{c d q}^{(3)}\right)\left(\frac{T_{s}}{4}-\frac{T_{z}}{4}-\frac{T_{1}}{2}\right)\right] \\
v_{c d q-a v}^{k-1}=0.5 \times\left(v_{c d q}^{(3)}+v_{c d q}^{(4)}\right)
\end{gathered}
$$

The grid voltage is assumed to be slowly varying, so for two consecutive samples, the $v_{g d q}$ components are assumed constant in (7 and 8$)$ and the discrete model can be rearranged as:

$$
\begin{aligned}
& i_{d}^{k}=2 i_{d}^{k-1}-i_{d}^{k-2}+\frac{T_{s}}{4}\left[\frac{1}{L}\left(v_{c d-a v}^{k-1}-v_{c d-a v}^{k-2}\right)-\frac{R}{L}\left(i_{d-a v}^{k-1}-i_{d-a v}^{k-2}\right)+\omega_{e}\left(i_{q-a v}^{k-1}-i_{q-a v}^{k-2}\right)\right] \\
& i_{q}^{k}=2 i_{q}^{k-1}-i_{q}^{k-2}+\frac{T_{s}}{4}\left[\frac{1}{L}\left(v_{c q-a v}^{k-1}-v_{c q-a v}^{k-2}\right)-\frac{R}{L}\left(i_{q-a v}^{k-1}-i_{q-a v}^{k-2}\right)-\omega_{e}\left(i_{d-a v}^{k-1}-i_{d-a v}^{k-2}\right)\right]
\end{aligned}
$$

The discrete models of the two consecutive samples given in (13 and 14) are analytically solved for the unknown parameters $(1 / L)$ and $(R / L)$ where $R$ and $L$ are the total resistance and inductance of the system.

After some algebraic manipulation, the solution for the unknown $(1 / L)$ and $(R / L)$ are given by $(15,16)$. It is worth noting that the derived inductance and resistance estimator models are fully decoupled and independent.

$$
\frac{1}{L}=\frac{\frac{4}{T_{s}}\left[\left(i_{d}^{k}-i_{d}^{k-1}\right)\left(i_{q-a v}^{k-1}-i_{q-a v}^{k-2}\right)-\left(i_{q}^{k}-i_{q}^{k-1}\right)\left(i_{d-a v}^{k-1}-i_{d-a v}^{k-2}\right)-\left(i_{d}^{k-1}-i_{d}^{k-2}\right)\left(i_{q-a v}^{k-1}-i_{q-a v}^{k-2}\right)+\left(i_{q}^{k-1}-i_{q}^{k-2}\right)\left(i_{d-a v}^{k-1}-i_{d-a v}^{k-2}\right)\right]}{-\omega_{e}\left[\left(i_{q-a v}^{k-1}-i_{q-a v}^{k-2}\right)^{2}+\left(i_{d-a v}^{k-1}-i_{d-a v}^{k-2}\right)^{2}\right]}
$$




$$
\frac{R}{L}=\frac{\frac{4}{T_{s}}\left[\left(i_{d}^{k}-i_{d}^{k-1}\right)\left(v_{c q-a v}^{k-1}-v_{c q-a v}^{k-2}\right)-\left(i_{q}^{k}-i_{q}^{k-1}\right)\left(v_{c d-a v}^{k-1}-v_{c d-a v}^{k-2}\right)-\left(i_{d}^{k-1}-i_{d}^{k-2}\right)\left(v_{c q-a v}^{k-1}-v_{c q-a v}^{k-2}\right)+\left(i_{q}^{k-1}-i_{q}^{k-2}\right)\left(v_{c d-a v}^{k-1}-v_{c d-a v}^{k-2}\right)\right]}{-\omega_{e}\left[\left(i_{q-a v}^{k-1}-i_{q-a v}^{k-2}\right)\left(v_{c q-a v}^{k-1}-v_{c q-a v}^{k-2}\right)+\left(i_{d-a v}^{k-1}-i_{d-a v}^{k-2}\right)\left(v_{c d-a v}^{k-1}-v_{c d-a v}^{k-2}\right)\right]}
$$

It should be noted that the $(R / L)$ estimator given by (16) is mainly dependent on the voltage difference and current derivatives measured between two consecutive samples. Furthermore, during the change of the current, the change of the voltage difference across the resistance will be very small. It means there is a high sensitivity to inaccurate measurements and averaging which will eventually lead to inaccurate estimates. As a result, the proposed impedance estimator technique is not capable of identifying the system resistance. Therefore, in the following sections only the inductance estimator is investigated.

An important practical issue that affects the accuracy of current measurement during the switching period is the high frequency current ringing that happens after turn on/off switching instants [21] due to parasitic inductances and capacitances within the power electronic system. In order to mitigate this problem, the estimation is disabled if the on/off instants have occurred less than $5 \mu$ s before the measuring instants (to allow the ringing to decay).

\section{Simulation Results}

The grid connected converter shown in Fig. 1 has been modelled using the SIMPOWER blockset in MATLAB using ideal power switches in the converter and parameters listed in Table 1. A random white Gaussian noise was added to the measured current to reflect realistic measurement noise and the inductance estimation (15) is performed alongside the simulation.

Table 1 System parameters.

\begin{tabular}{ccc}
\hline symbol & meaning & value \\
\hline$R_{f}$ & Filter Resistance & $0.12 \Omega$ \\
$L_{f}$ & Filter inductance & $1.93 \mathrm{mH}$ \\
$R_{g}$ & Grid Resistance & $0.113 \Omega$ \\
$L_{g}$ & Grid inductance & $0.54 \mathrm{mH}$ \\
$V_{g}$ & Grid voltage & $120 \mathrm{~V}$ \\
$V_{d c}$ & DC-link voltage & $250 \mathrm{~V}$ \\
$f_{s}$ & switching frequency & $10 \mathrm{kHz}$ \\
\hline
\end{tabular}

\subsection{Inductance estimation at different grid parameters}

Fig. 2 shows the simulation results for system inductance estimation with different grid impedance parameters. The grid resistance is changed at $\mathrm{t}=0.1 \mathrm{~s}$ from $0.113 \Omega$ to $0.5 \Omega$ and the grid inductance is increased at $\mathrm{t}=0.2 \mathrm{~s}$ from $0.54 \mathrm{mH}$ to $1.43 \mathrm{mH}$. The results show an accurate estimation of the change in grid inductance (even in the presence of measurement noise) with insensitivity to resistance variations. The ramp in the estimated inductance is caused by a rate limit $(10 \mathrm{H} / \mathrm{s})$ which has been added to the estimator to reduce the effect of noise and measurement filtering. Fig. 2-b shows the instants at which the inductance estimation is disabled to avoid the switching instant ringing/oscillation. Their effect on the inductance estimation process is negligible.

\subsection{Islanding detection test}

One important application of the grid inductance estimation is islanding detection. A simulation scenario to show the use of the inductance estimator for islanding detection is given in Fig. 3-a and the results are shown in Fig. 3-b.The converter is connected to a grid made up of two connections; one is strong and the other is weak. The strong connection in Fig. 4 is disconnected at $t=0.1 \mathrm{~s}$ and the estimated inductance changes to a higher value (see Fig. 3-b) within $50 \mathrm{~ms}$ - close to two supply periods. This is fast enough for the change in the estimated inductance to be used as a flag for islanding. 


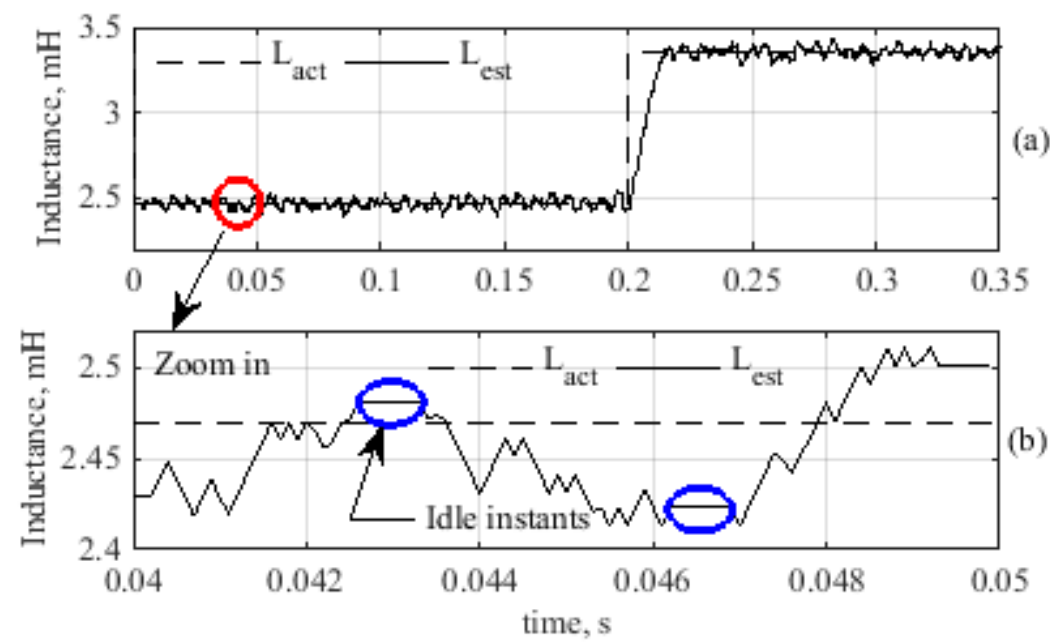

Fig. 2. The estimated inductance for different grid parameters.

a The estimated inductance variation at different grid resistance and inductance.

b Zoom in shows estimation idle instants.

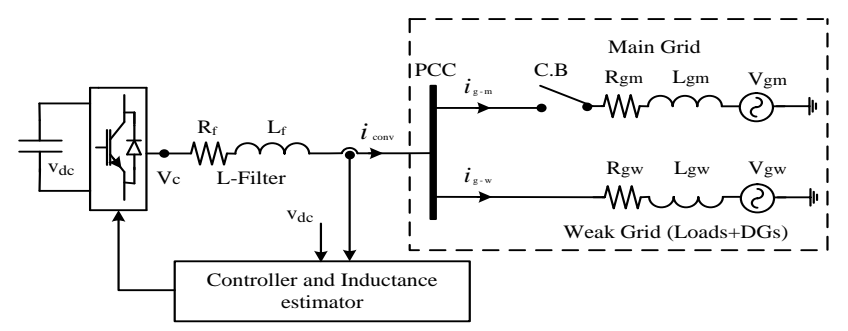

a
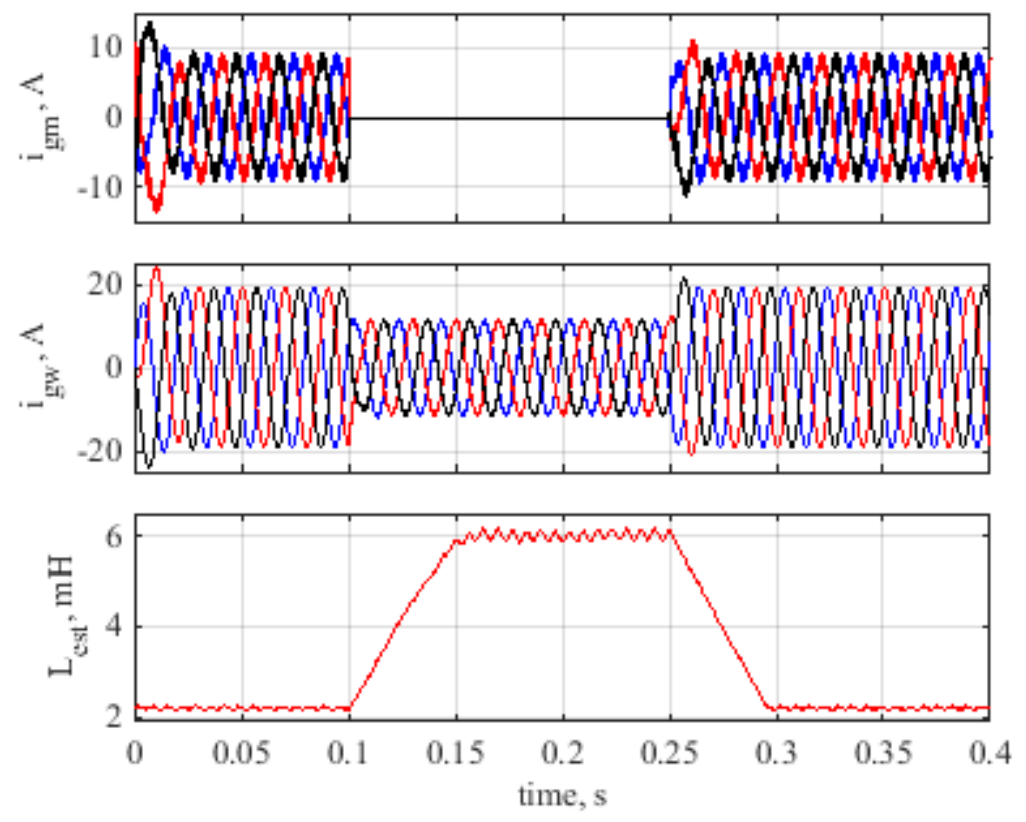

b

Fig. 3. Application of the estimated inductance for Islanding.

a Islanding test system configuration.

b Simulation results for islanding detection. 


\subsection{Adaptive current control}

In this section, the estimated inductance is used for online current control loop tuning. The closed loop transfer function of the reference current to the actual current is given by:

$$
C(s)=\frac{I(s)}{I^{*}(s)}=\frac{\frac{1}{L}\left(K_{I}+K_{p} S\right)}{S^{2}+\frac{1}{L}\left(R+K_{p}\right) S+\frac{K_{I}}{L}}
$$

The second order system given by the closed loop transfer function has an undamped natural frequency of $\omega_{n}=$ $\sqrt{K_{I} / L}$ and damping ratio of $\xi=0.5 \sqrt{\frac{1}{K_{I} \cdot L}}\left(R+K_{p}\right)$. The controller parameters $K_{p}$ and $K_{I}$ are adaptively calculated to achieve a specific bandwidth and damping ratio based on the estimated inductance. The magnitude of the closed loop transfer function $\left|C\left(j \omega_{b w}\right)\right|$ is set to be $-3 \mathrm{~dB}$ at the required bandwidth and damping ratio as given by $(18,19)$.

$$
\begin{gathered}
\left|C\left(j \omega_{b w}\right)\right|=\left[\frac{\left(\frac{\omega_{b w} K p}{L}\right)^{2}+\left(\frac{R+K p}{2 L \xi}\right)^{4}}{\left(\omega_{b w}\right)^{2}\left(\frac{R+K p}{L}\right)^{2}+\left[\left(\frac{R+K p}{2 L \xi}\right)^{2}-\left(\omega_{b w}\right)^{2}\right]^{2}}\right]^{1 / 2}=\frac{1}{\sqrt{2}} \\
K_{i}=\frac{1}{L}\left(\frac{R+K_{p}}{2 \xi}\right)^{2}
\end{gathered}
$$

Equation (18) is solved using the Newton-Raphson iterative method for $K_{p}$ and then $K_{i}$ is calculated using (19) to achieve a bandwidth of $200 \mathrm{~Hz}$ and damping ratio of 0.8 . The adaptive parameters are updated once every sampling period and the same PI parameters are used for both the $d$ and $q$ current loops.

The tuning of the PI parameters due to change of the grid inductance is presented in Fig. 4-a. It can be seen that at $\mathrm{t}=0.05 \mathrm{~s}$ the grid inductance is increased to $2 \mathrm{mH}$ giving a total inductance of $3.93 \mathrm{mH}$. During the change of the estimated inductance, the PI parameters are also tuned to achieve the specified bandwidth and damping ratio. Once the new inductance is estimated and becomes constant, the PI parameters also become steady.

The time step response at different grid inductance values without and with the adaptive PI controller for $d$ and $q$ axes control loops are presented in Fig. 4-b. Obviously, it can be seen that without the PI parameter adaptation, an increase in the grid inductance affects the performance of the controller and decreases its bandwidth. In contrast, with the adaptive PI controller, the same step response before and after the grid impedance change is achieved.

\section{Experimental Evaluation of Online inductance estimation}

An experimental system has been constructed to evaluate the challenges of implementing this impedance measurement technique on a representative power electronic converter.

The converter controller was implemented using a Texas Instruments TMS320C6713 DSK board alongside a bespoke Actel FPGA A3P400 based data acquisition board and Host Port Interface (HPI) daughter card for user interaction. The DSP board has a clock frequency of $225 \mathrm{MHz}$ while the FPGA board has a clock frequency of 50 $\mathrm{MHz}$ and has ten channels of Analogue to Digital Converters (ADCs). The dc-side was set at $250 \mathrm{~V}$ and the converter operated in rectifier mode feeding load resistors on the DC side. Note that the tests were performed using switching frequencies of both $5 \mathrm{kHz}$ and $10 \mathrm{kHz}$.

The ac supply used for the microgrid was a Chroma 61511 programmable AC source, which can provide an ideal sinusoidal supply and also harmonic content. An inductive filter is used to connect the converter to PCC, and two parallel inductors $\left(L_{1}, L_{2}\right)$ are used to represent the grid impedance between PCC and the ideal source, as shown in Fig. 5-a. In addition, a circuit breaker (C.B) is used in series with the inductor $L_{2}$ in order to switch it in and out of circuit to vary the grid impedance. 

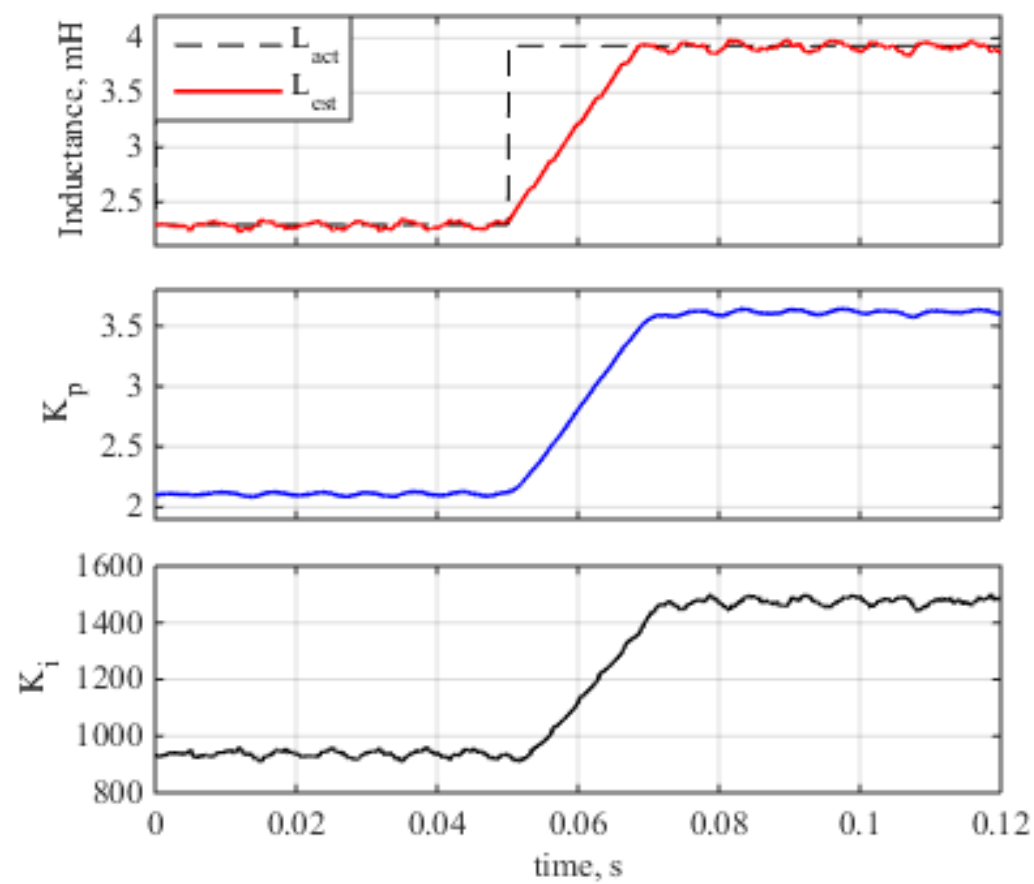

a
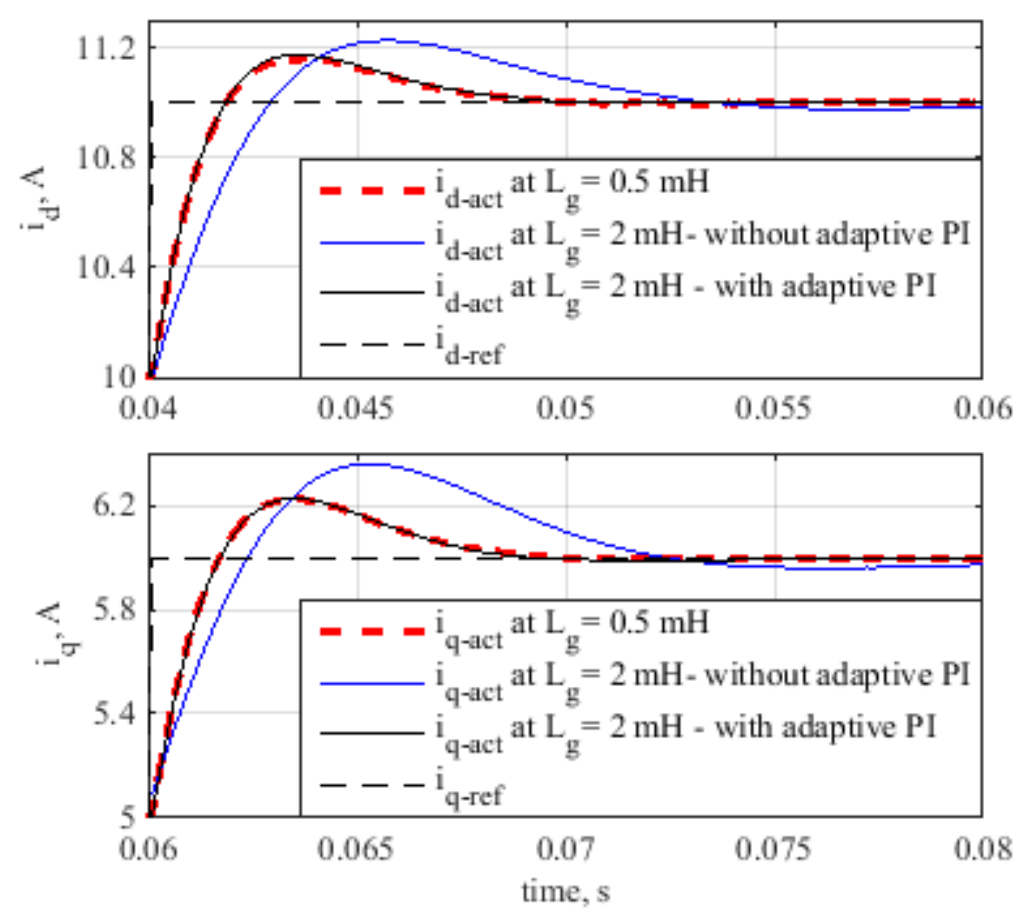

$\mathrm{b}$

Fig. 4. Application of the estimated inductance for current control loop tunning.

a Adaptation of PI parameter with grid inductance variation.

b Time step response. 


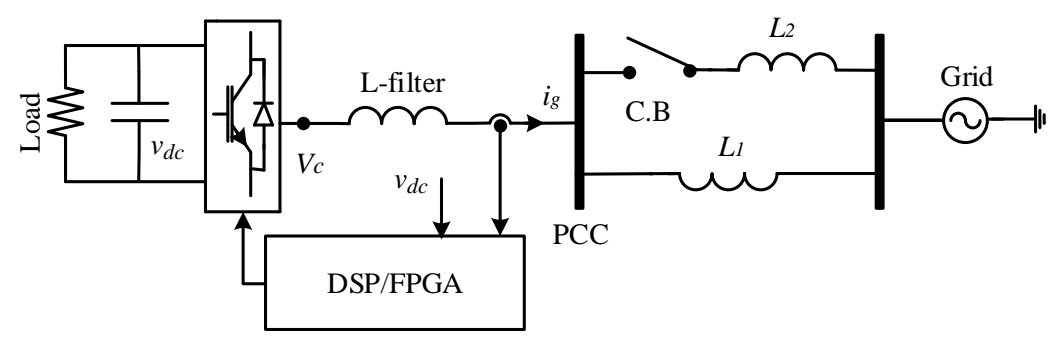

a
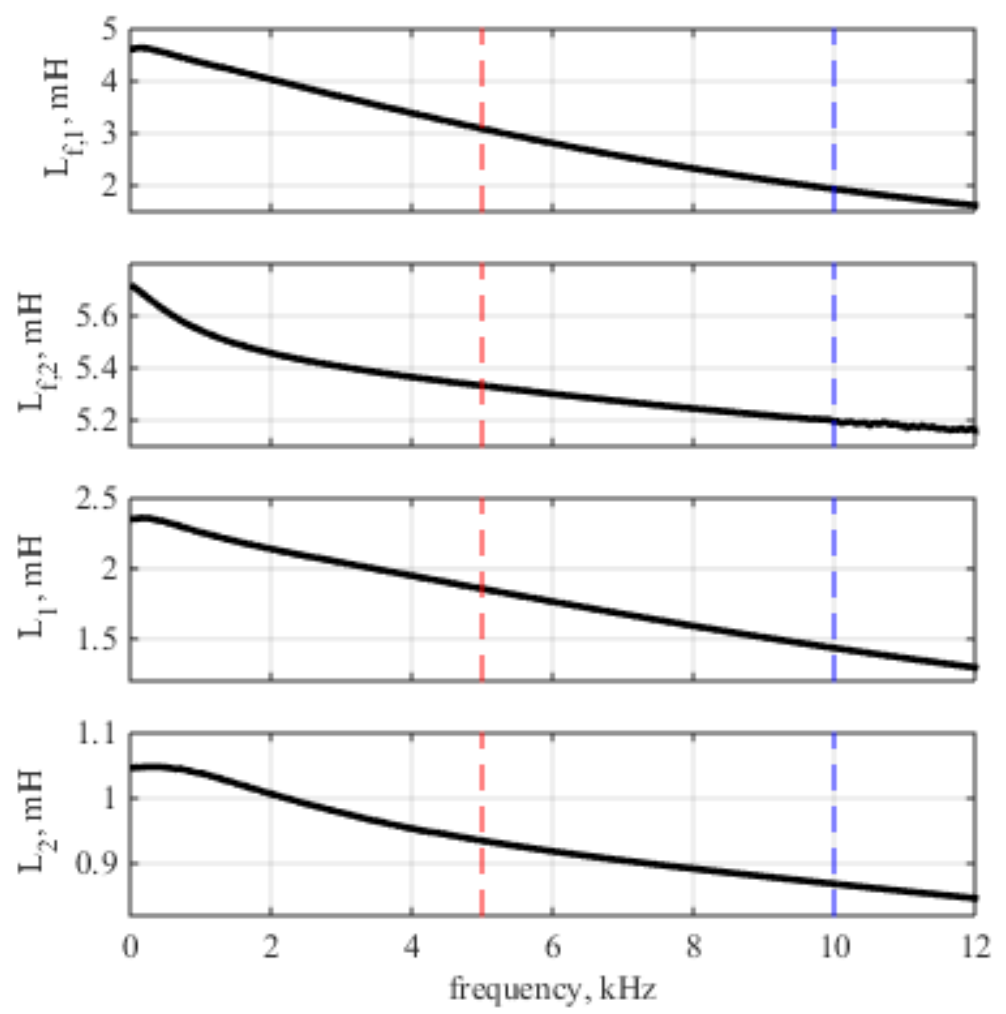

b

Fig. 5. Experimental setup.

a Experimental setup configuration.

b Inductance value measured at different frequencies using LCR bridge.

To investigate the effectiveness of the proposed estimation method for differing grid scenarios, two scenarios were defined:

Scenario \#1: The $L$ - filter $\left(L_{f, 1}\right)$ was used with both "grid" inductors $\left(L_{1}, L_{2}\right)$ connected in parallel. The values of the three coils $L_{f, 1}, L_{1}$ and $L_{2}$ were measured at different frequencies using a PSM1735 LCR meter and their values are plotted and given in Fig. 5-b. The total (calibrated) inductance values are $2.47 \mathrm{mH}$ and $3.73 \mathrm{mH}$ at $10 \mathrm{kHz}$ and 5 $\mathrm{kHz}$ respectively. When $L_{2}$ has been disconnected by opening the C.B (see Fig. 5-a), the total (calibrated) inductance values are $3.36 \mathrm{mH}$ and $5 \mathrm{mH}$ at $10 \mathrm{kHz}$ and $5 \mathrm{kHz}$ respectively.

Scenario \#2: The filter inductor is replaced by a standard three-phase iron-core coil inductor $\left(L_{f, 2}\right)$ with a value of $5.2 \mathrm{mH}$ at $10 \mathrm{kHz}$ and $5.33 \mathrm{mH} 5 \mathrm{kHz}$ as shown in Fig. (5-b). The inductor $\left(L_{l}\right)$ is replaced by a $5 \mathrm{mH}$ ferrite core inductor and its inductance is constant over the frequency range of interest. The inductor $\left(L_{2}\right)$ is kept the same. Before disconnecting $L_{2}$, the total calibrated inductance values are $5.94 \mathrm{mH}$ and $6.11 \mathrm{mH}$ at $10 \mathrm{kHz}$ and $5 \mathrm{kHz}$ respectively. After disconnecting $L_{2}$, these values change to $10.2 \mathrm{mH}$ and $10.33 \mathrm{mH}$ at $10 \mathrm{kHz}$ and $5 \mathrm{kHz}$ respectively.

The key challenge to the real-time implementation is coordinating the capture of current measurements with the switching edges created by the PWM routine. The current has been measured three times within the interrupt 
service routine (ISR) (at the beginning, a quarter and half the way through the switching period). The timing of these measurements within the interrupt period is achieved using time delay counters. The inductance is calculated every interrupt period using these three measurements, using the closed form given in (15). A change rate limit is then applied based on the present and previous value of the calculated inductance in order to alleviate the effect of measurement noise. The HPI interface daughter card provides a user interface and allows the user to modify and monitor the parameters within the ISR using the MATLAB environment.

It is worth mentioning that proposed method has been evaluated under ideal and distorted grid voltage conditions. For the distorted grid, the Chroma output voltage was modified to include five percent of $5^{\text {th }}$ and $7^{\text {th }}$ harmonic orders.

Fig. 6 shows the experimental results for scenario \#1 at a switching frequency of $10 \mathrm{kHz}$ with an ideal and distorted grid voltage. It can be seen when operating with an ideal grid voltage (i.e., fundamental only), the total inductance is estimated online as $2.3 \mathrm{mH}$ compared to the calibrated value of $2.47 \mathrm{mH}$ before the disconnection of $L_{2}$. The estimated value is $3.9 \mathrm{mH}$ compared to the calibrated value of $3.36 \mathrm{mH}$ after the disconnection of $L_{2}$ (see Fig. 6a). When harmonics are introduced into the grid voltage, the total inductance is estimated as $2.6 \mathrm{mH}$ before the disconnection of $L_{2}$ and $4.7 \mathrm{mH}$ after the disconnection of $L_{2}$ (see Fig. 6-b).
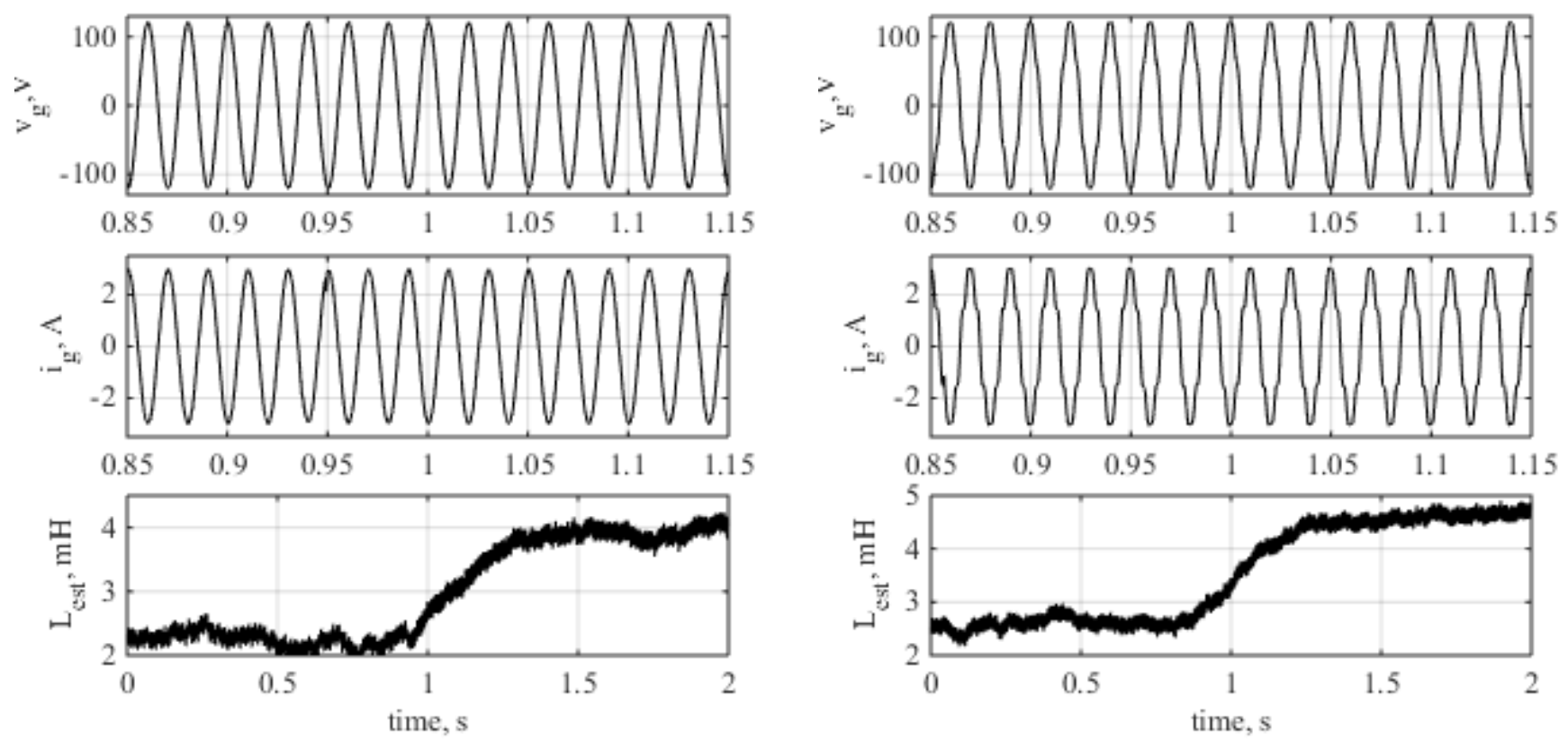

a

$\mathrm{b}$

Fig. 6. Estimated inductance for scenario \# 1 at switching frequency of $10 \mathrm{kHz}$.

a Estimated inductance with ideal grid voltage.

b Estimated inductance with grid voltage harmonics.

The inductance estimation for scenario \#1 was also investigated at switching frequency of $5 \mathrm{kHz}$ and the online experimental results are shown in Fig. 7. For the operation with fundamental grid voltage only, the total inductance is estimated as $3.7 \mathrm{mH}$ compared to its calibrated value of $3.73 \mathrm{mH}$ before the disconnection of $L_{2}$ and 4.7 $\mathrm{mH}$ compared to its calibrated value of $5 \mathrm{mH}$ after the disconnection of $L_{2}$ (see Fig. 7-a). After harmonics are introduced into the supply voltage, the total inductance is estimated as $4 \mathrm{mH}$ before the disconnection of $L_{2}$ and as 5.2 $\mathrm{mH}$ after the disconnection of $L_{2}$ (see Fig. 7-b). 

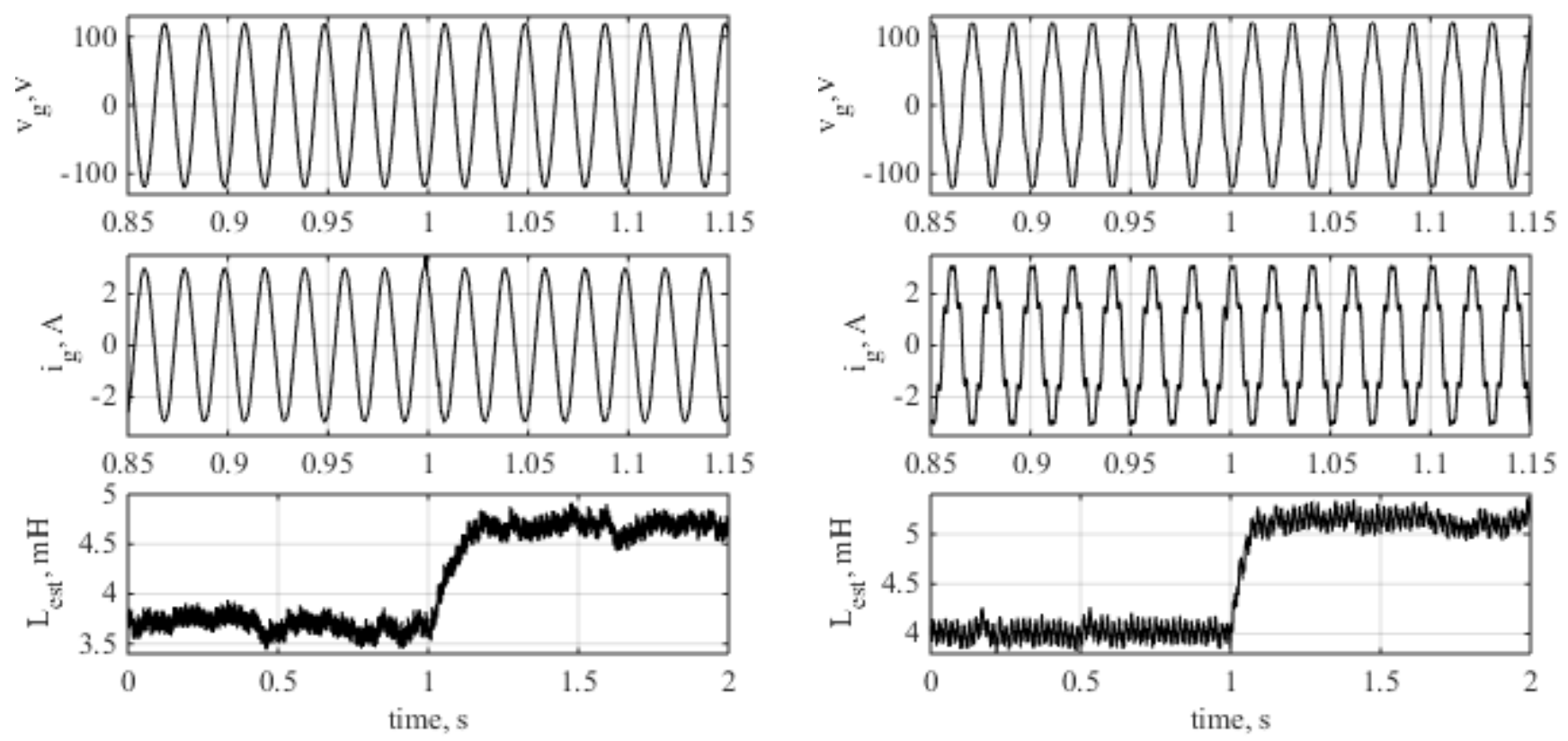

a

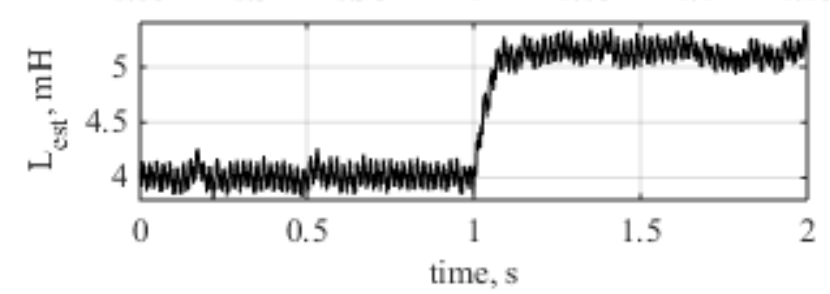

b

Fig. 7. Estimated inductance for scenario \#1 at switching frequency of $5 \mathrm{kHz}$.

a Estimated inductance with ideal grid voltage.

b Estimated inductance with grid voltage harmonics.

Fig. 8 shows the experimental results for scenario \#2 at a switching frequency of $10 \mathrm{kHz}$. It can be seen that at the operation with only fundamental grid voltage, the total inductance is estimated as $6.8 \mathrm{mH}$ compared to its calibrated value of $5.94 \mathrm{mH}$ before the disconnection of $L_{2}$ and $12.2 \mathrm{mH}$ compared to its calibrated value of $10.2 \mathrm{mH}$ after the disconnection of $L_{2}$ (see Fig. 8-a). When harmonics are added to the grid voltage, the total inductance is estimated as $7.2 \mathrm{mH}$ before the disconnection of $L_{2}$ and $13.6 \mathrm{mH}$ after the disconnection of $L_{2}$ (see Fig. 8-b).
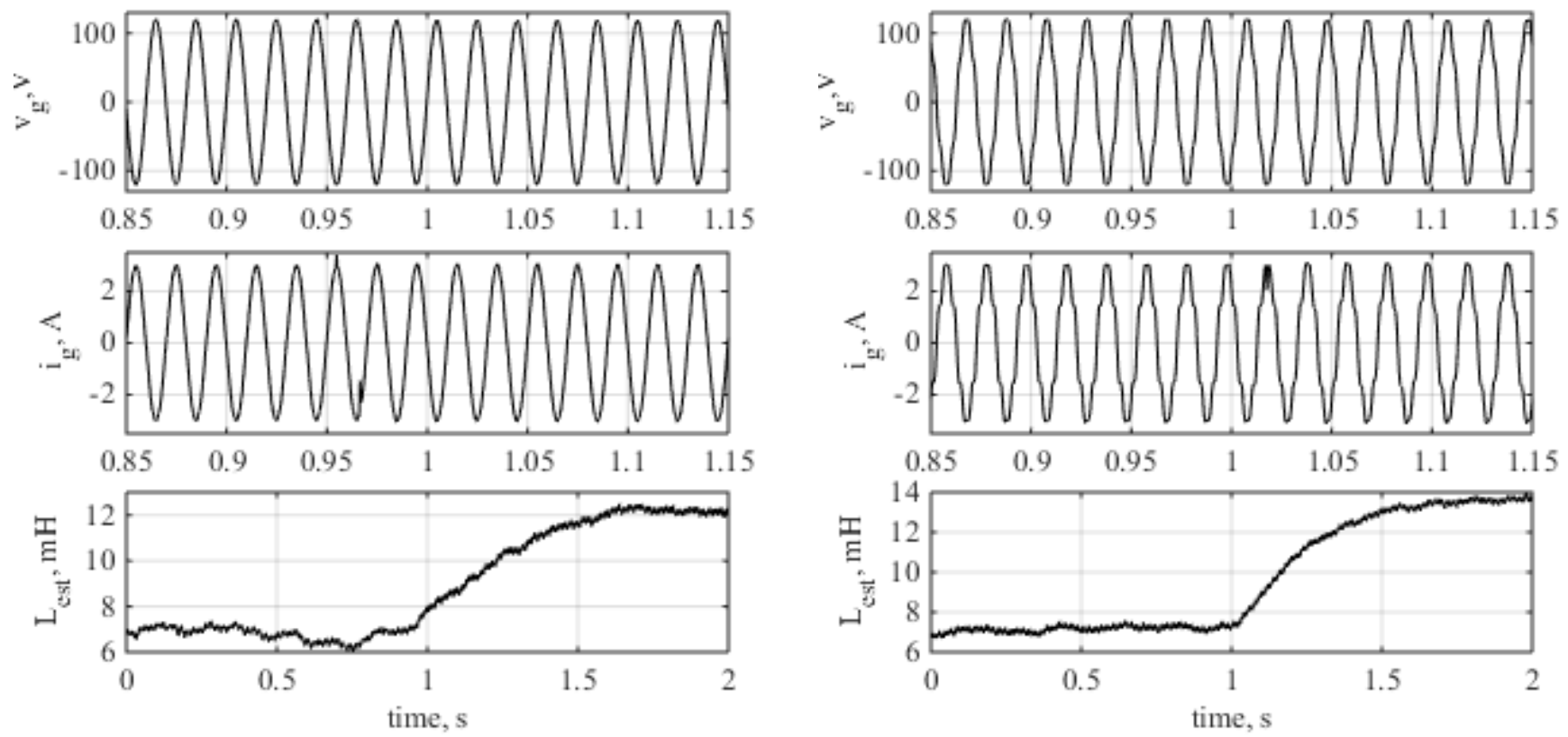

a

b

Fig. 8. Estimated inductance for scenario \#2 at switching frequency of $10 \mathrm{kHz}$.

a Estimated inductance with ideal grid voltage.

b Estimated inductance with grid voltage harmonics. 
The experimental results for a switching frequency of $5 \mathrm{kHz}$ for scenario \#2 are shown in Fig. 9. When operating with an ideal grid voltage, the total inductance is estimated as $6.5 \mathrm{mH}$ compared to its calibrated value of $6.11 \mathrm{mH}$ before the disconnection of $L_{2}$ and $9.8 \mathrm{mH}$ compared to its calibrated value of $10.33 \mathrm{mH}$ after the disconnection of $L_{2}$ (see Fig. 9-a). When operating with a distorted grid voltage, the total inductance is estimated as $6.6 \mathrm{mH}$ before the disconnection of $L_{2}$ and $12.1 \mathrm{mH}$ after the disconnection of $L_{2}$ (see Fig. 9-b).

The combined results for these tests are given in Table 2 .
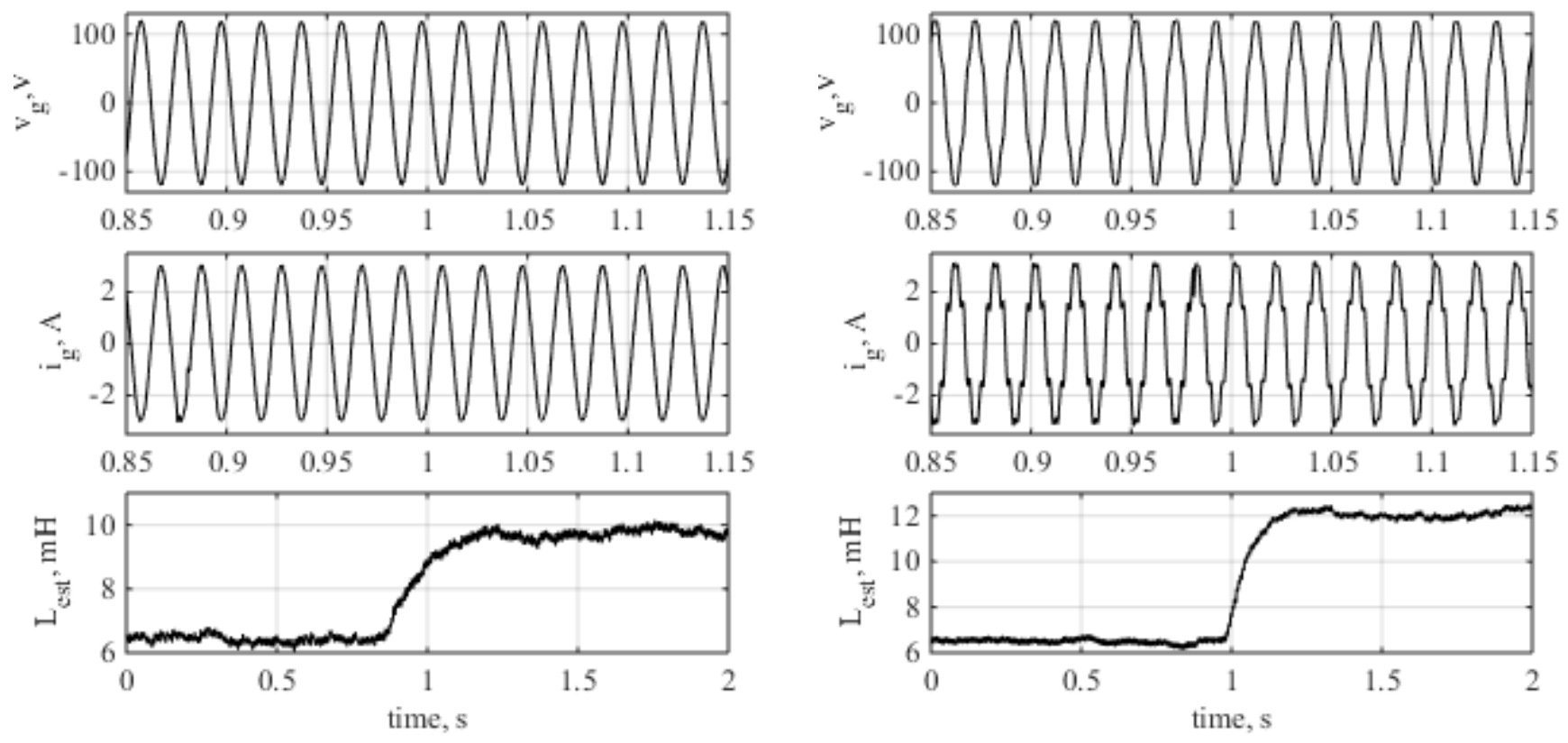

a

b

Fig. 9. Estimated inductance for scenario \#2 at switching frequency of $5 \mathrm{kHz}$.

a Estimated inductance with ideal grid voltage.

b Estimated inductance with grid voltage harmonics.

Table 1 Summary of the estimated inductance value.

\begin{tabular}{lccc}
\hline \multicolumn{1}{c}{ State } & $\begin{array}{c}\text { Calibrated } \\
\text { inductance, } \mathrm{mH}\end{array}$ & $\begin{array}{c}\text { Estimated } \\
\text { inductance, mH }\end{array}$ & \% error \\
\hline Scenario\#1: $L_{2}$ connected (10 kHz, "ideal" grid) & 2.47 & 2.3 & -6 \\
Scenario\#1: $L_{2}$ disconnected (10 kHz, "ideal” grid) & 3.36 & 3.9 & 16 \\
Scenario\#1: $L_{2}$ connected (10 kHz, "distorted" grid) & 2.47 & 2.6 & 5 \\
Scenario\#1: $L_{2}$ disconnected (10 kHz, "distorted" grid) & 3.36 & 4.7 & 39 \\
Scenario\#1: $L_{2}$ connected (5 kHz, "ideal" grid) & 3.73 & 3.7 & -0.8 \\
Scenario\#1: $L_{2}$ disconnected (5 kHz, "ideal" grid) & 5 & 4.7 & 6 \\
Scenario\#1: $L_{2}$ connected (5 kHz, "distorted" grid) & 3.73 & 4 & 7 \\
Scenario\#1: $L_{2}$ disconnected (5 kHz, "distorted" grid) & 5 & 5.2 & 4 \\
Scenario\#2: $L_{2}$ connected (10 kHz, "ideal" grid) & 5.94 & 6.8 & 14 \\
Scenario\#2: $L_{2}$ disconnected (10 kHz, "ideal" grid) & 10.2 & 12.2 & 19 \\
Scenario\#2: $L_{2}$ connected (10 kHz, "distorted" grid) & 5.94 & 7.2 & 21 \\
Scenario\#2: $L_{2}$ disconnected (10 kHz, "distorted" grid) & 10.2 & 13.6 & 34 \\
Scenario\#2: $L_{2}$ connected (5 kHz, "ideal" grid) & 6.11 & 6.5 & 6 \\
Scenario\#2: $L_{2}$ disconnected (5 kHz, "ideal" grid) & 10.33 & 9.8 & -5 \\
Scenario\#2: $L_{2}$ connected (5 kHz, "distorted" grid) & 6.11 & 6.6 & 8 \\
Scenario\#2: $L_{2}$ disconnected (5 kHz, "distorted" grid) & 10.33 & 12.1 & 17 \\
\hline
\end{tabular}


It is clear from Figs. 6 to 8 that the grid inductance estimator can identify changes in supply impedance when implemented in an experimental system. However it is also clear from Table 2 that the error in the estimation is dependent on operating conditions and is certainly higher than seen in the simulation studies. There are significant differences between the simulation and experimental systems: measurement noise is more prominent, especially as the measurements used are taken close to the switching of power converters; the timing of the measurements is dependent on both the resolution of the system clock and the interrupt latency associated with the measurement time and errors in these timings can have a large effect on the accuracy of the non-averaged terms of (15). Other real phenomena such as semiconductor nonlinearities, device voltage drop, dead time, antialiasing filters and current sensor accuracy will all influence the behaviour of this estimator.

For example, the results of Table 2 show that the proposed inductance estimator has improved accuracy when employed at a lower switching frequency. This is likely to be due to the increased amplitude of the current ripple (even when the grid voltage is distorted) which reduces the effect of measurement noise and improves the resolution. The lower switching frequency will also reduce the influence of timing delays in the sampling and PWM processes. More investigation is required to determine the relative influences of these phenomena on the accuracy of the identification algorithm. However, even in this early experimental implementation the proposed inductance estimator can effectively detect the variation of inductance even with a distorted grid voltage.

\section{Conclusion}

Closed-form grid inductance and resistance estimation models have been derived from the discrete grid connected converter modelled in the dq reference frame. The estimators use two consecutive current samples measured within a single SVPWM switching period. The derived inductance and resistance estimator models are fully decoupled and independent. The effectiveness of the proposed estimation approach for islanding detection and adaptive tuning (online) of the PI current controller gains have verified by simulation even in the presence of representative measurement noise. Experimental results demonstrate that the proposed impedance estimator can detect changes in grid impedance although its accuracy is lower than expected. The proposed method has been shown to be more effective when a low switching frequency is used. It is thought that the lower accuracy in the experimental system is due to errors in the timing of the measurements made in the experimental system: the accuracy improves as the switching period becomes higher and the influence of timing errors reduces. Future work will investigate this further. Other applications of the proposed method include converters for motor drives which use an $L$-only filter or that connect directly to the machine e.g., permanent magnet synchronous machine drives. Furthermore, it can be as the basis of a portable device to measure the grid inductance at specific network positions.

\section{References}

[1] Guo, X.Q., Zhang, X., Wang, B.C., et al.:'Asymmetrical grid fault ride-through strategy of three-phase grid-connected inverter considering network impedance impact in low-voltage grid', IEEE Transactions on Power Electronics, 2014, 29, (3), pp. 1064-1068

[2] Strasser, T., Andren, F., Kathan, J., et al.:'A review of architectures and concepts for intelligence in future electric energy systems', IEEE Transactions on Industrial Electronics, 2015, 62, (4), pp. 2424-2438

[3] Sumner, M., Abusorrah, A., Thomas, D., et al.:'Real time parameter estimation for power quality control and intelligent protection of grid-connected power electronic converters', IEEE Transactions on Smart Grid, 2014, 5, (4), pp. 1602-1607

[4] Ciobotaru, M., Teodorescu, R., Rodriguez, P., et al.:"Online grid impedance estimation for single-phase grid-connected systems using PQ variations', in, 2007 IEEE Power Electronics Specialists Conference, 2007

[5] Crevier, D. and Mercier, A.:'Estimation of Higher Frequency Network Equivalent Impedances by Harmonic Analysis Natural Waveforms', IEEE Transactions on Power Apparatus and Systems, 1978, PAS-97, (2), pp. 424-431

[6] Girgis, A.A. and McManis, R.B.:'Frequency domain techniques for modeling distribution or transmission networks using capacitor switching induced transients', IEEE Transactions on Power Delivery, 1989, 4, (3), pp. 1882-1890

[7] Herong, G., Guo, X., Deyu, W., et al.:"Real-time grid impedance estimation technique for grid-connected power converters', in, Industrial Electronics (ISIE), 2012 IEEE International Symposium on, 2012

[8] Liserre, M., Blaabjerg, F., and Teodorescu, R.:'Grid impedance estimation via excitation of LCL-filter resonance', IEEE Transactions on Industry Applications, 2007, 43, (5), pp. 1401-1407 
[9] Hoffmann, N. and Fuchs, F.W.:'Minimal invasive equivalent grid impedance estimation in inductive-resistive power networks using extended kalman filter', IEEE Transactions on Power Electronics, 2014, 29, (2), pp. 631-641

[10] Arif, B., Tarisciotti, L., Zanchetta, P., et al.:'Grid parameter estimation using model predictive direct power control', IEEE Transactions on Industry Applications, 2015, 51, (6), pp. 4614-4622

[11] Cespedes, M. and Sun, J.:'Online grid impedance identification for adaptive control of grid-connected inverters', in, 2012 IEEE Energy Conversion Congress and Exposition (ECCE), 2012

[12] Palethorpe, B., Sumner, M., and Thomas, D.W.P.:'Power system impedance measurement using a power electronic converter', in, Harmonics and Quality of Power, 2000. Proceedings. Ninth International Conference on, 2000

[13] Sumner, M., Thomas, D.W.P., and Zanchetta, P.:'Power System Impedance Estimation for Improved Active Filter Control, using Continuous Wavelet Transforms', in, 2005/2006 IEEE/PES Transmission and Distribution Conference and Exhibition, 2006

[14] Asiminoaei, L., Teodorescu, R., Blaabjerg, F., et al.:'Implementation and test of an online embedded grid impedance estimation technique for PV inverters', IEEE Transactions on Industrial Electronics, 2005, 52, (4), pp. 1136-1144

[15] Ciobotaru, M., Teodorescu, R., and Blaabjerg, F.:'On-line grid impedance estimation based on harmonic injection for gridconnected PV inverter', in, 2007 IEEE International Symposium on Industrial Electronics, 2007

[16] Neshvad, S., Chatzinotas, S., and Sachau, J.:'Wideband identification of power network parameters using pseudo-random binary sequences on power inverters', IEEE Transactions on Smart Grid, 2015, 6, (5), pp. 2293-2301

[17] Zhou, J.Z., Ding, H., Fan, S.T., et al.:'Impact of short-circuit ratio and phase-locked-loop parameters on the small-signal behavior of a VSC-HVDC converter', IEEE Transactions on Power Delivery, 2014, 29, (5), pp. 2287-2296

[18] Li, D., Notohara, Y., Iwaji, Y., et al.:'AC voltage and current sensorless control method for three - phase PWM converter' , Electrical Engineering in Japan, 2010, 172, (4), pp. 48-57

[19] Shu, Z.L., Tang, J., Guo, Y.H., et al.:'An efficient SVPWM algorithm with low computational overhead for three-phase inverters', IEEE Transactions on Power Electronics, 2007, 22, (5), pp. 1797-1805

[20] Siwakoti, Y.P. and Town, G.E.:'Design of FPGA-controlled power electronics and drives using MATLAB simulink', in, ECCE Asia Downunder (ECCE Asia), 2013 IEEE, 2013

[21] Ginart, A.E., Brown, D.W., Kalgren, P.W., et al.:'Online ringing characterization as a diagnostic technique for IGBTs in power drives', IEEE Transactions on Instrumentation and Measurement, 2009, 58, (7), pp. 2290-2299 